\title{
Les chansons de Colin Muset, Textes et mélodies. Éditées par Christopher Callahan et Samuel N. Rosenberg
}

\author{
Maria Colombo Timelli
}

\section{(2) OpenEdition}

Journals

Édition électronique

URL : http://journals.openedition.org/studifrancesi/27198

DOI : 10.4000/studifrancesi.27198

ISSN : 2421-5856

Éditeur

Rosenberg \& Sellier

\section{Édition imprimée}

Date de publication : 31 décembre 2006

Pagination : 575

ISSN : 0039-2944

\section{Référence électronique}

Maria Colombo Timelli, « Les chansons de Colin Muset, Textes et mélodies. Éditées par Christopher Callahan et Samuel N. Rosenberg », Studi Francesi [En ligne], 150 (L | III) | 2006, mis en ligne le 30 novembre 2015, consulté le 08 novembre 2020. URL : http://journals.openedition.org/studifrancesi/ 27198 ; DOI : https://doi.org/10.4000/studifrancesi.27198

Ce document a été généré automatiquement le 8 novembre 2020.

\section{c) $(9 \ominus$}

Studi Francesi è distribuita con Licenza Creative Commons Attribuzione - Non commerciale - Non opere derivate 4.0 Internazionale. 


\title{
Les chansons de Colin Muset, Textes et mélodies. Éditées par Christopher Callahan et Samuel N. Rosenberg
}

\author{
Maria Colombo Timelli
}

\section{RÉFÉRENCE}

Les chansons de COLIN MUSET, Textes et mélodies. Éditées par Christopher CALLAHAN et Samuel N. ROSENBERG, Paris, Champion («Classiques français du Moyen Âge», 149), 2004, pp. 240.

1 Colin Muset jouit en ce moment d'un intérêt accru, puisque deux éditions / traductions ont paru en 2005 à quelques mois seulement de distance: Massimiliano Chiamenti vient de reproposer l'édition de Bédier (1938) accompagnée d'une traduction italienne en prose et d'un important commentaire littéraire (Roma, Carocci, 2005: cf. SF 149, 2005, p. 363). Christopher Callahan et Samuel N. Rosenberg offrent maintenant une nouvelle édition critique et une traduction en français moderne publiée à part.

2 L'édition, amplement et sérieusement justifiée (pp. 16-20), élargit le corpus retenu par Bédier: elle comprend en effet 22 poèmes, en englobant les chansons dont l'attribution reste douteuse, et surtout elle inclut la mélodie. L'Introduction rappelle rapidement les rares données biographiques et la thématique chère à Muset (pp. 9-16); elle est surtout consacrée aux questions philologiques, particulièrement embrouillées lorsque l'on décide de discuter et de tenir compte en même temps des aspects littéraires et musicaux. Les attributions sont attentivement examinées et les critères qui ont présidé au choix d'éditer chaque poème clairement exposés (pp. 20-33). L'étude linguistique (pp. 33-37) est synthétique, mais ne néglige pas de séparer ce qui peut raisonnablement être attribué à l'auteur et ce qui caractérise en revanche la langue des différents chansonniers. La présentation des formes lyriques (chansons et lais-descorts) fait ressortir l'originalité de Muset, sa volonté d'essayer des schémas de rimes et de mètres 
souvent uniques, dont rendent amplement compte les tableaux dressés par les éditeurs (pp. 70-87). La musique fait l'objet d'une étude à part, qui met surtout en relief le rapport fondamental entre texte et mélodie (pp. 57-69; on se rapportera aussi aux tableaux des pp. 88-91). Les principes d'édition sont soigneusement exposés, le problème fondamental concernant le choix des textes bases: treize poèmes sont transmis par un seul manuscrit; pour les neuf autres, les éditeurs ont dû opter pour l'un ou l'autre chansonnier en fonction de la qualité de chaque texte. Bibliographie complète aux pp. 99-109. L'édition des poèmes présente dans l'ordre: la mélodie, le texte, la liste des manuscrits, l'apparat critique (leçons rejetées et variantes), le schéma de la versification, le schéma mélodique, les renvois aux éditions précédentes et les remarques (littéraires et philologiques) sur le texte et sur la musique. Il s'agit dans l'ensemble d'une édition très riche, que complètent utilement l'Index des noms propres (pp. 219-222), un glossaire considérablement élargi (pp. 223-236) et la table des incipit (et concordance avec les répertoires, p. 237).

3 Le petit volume complémentaire, avec la traduction en français moderne, ne renonce pas à une introduction essentielle, qui présente la tradition du texte et rappelle avec intelligence les thèmes coliniens bien connus des médiévistes (le confort matériel, l'amour, le chant) ainsi que les rôles joués par Colin Muset dans ses poèmes: jongleur, fin amant, bon vivant, présent et absent en même temps dans sa poésie, brossant un autoportrait qui fascine toujours, dont on n'est pas en mesure de connaitre la part d'authenticité. La Bibliographie - organisée ici par sujets - reprend celle de l'édition (pp. 21-30). La traduction, dont les principes sont rapidement esquissés p. 19, suit le lignage des vers sans prétendre naturellement reproduire le rythme et la rime des originaux. 